\title{
Dos anuarios imprescindibles y complementarios: Anuario de Bibliotecas Españolas 2008 y Anuario ThinkEPI 2008
}

\author{
Por Luis Rodríguez-Yunta
}

Rodríguez-Yunta, Luis. "Dos anuarios imprescindibles y complementarios: Anuario de Bibliotecas Españolas 2008 y Anuario ThinkEPI 2008”. En: El profesional de la información, 2008, julio-agosto, v. 17, n. 4, pp. 473-474.

DOI: $10.3145 /$ epi.2008.jul.18

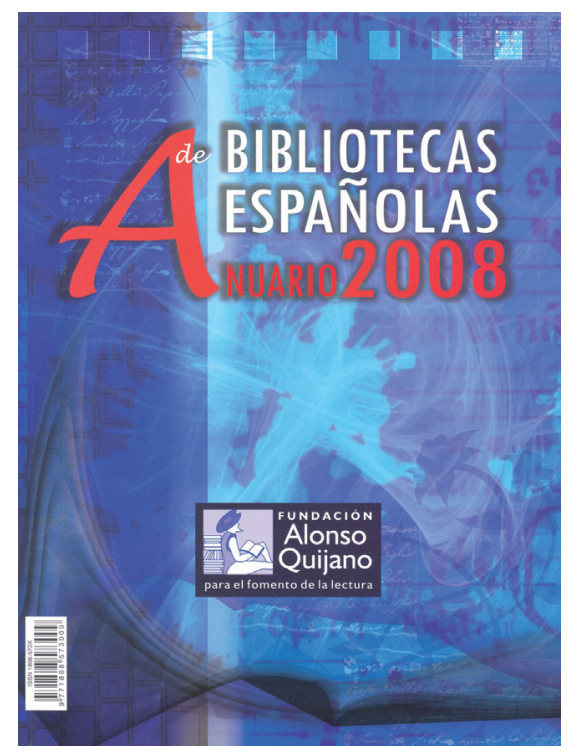

Anuario de

Bibliotecas Españolas 2008. Málaga:

Fundación Alonso

Quijano, 2008. ISSN:

$1888-573 \mathrm{X}$.

UN ANUARIO representa un modelo de publicación periódica que a menudo puede calificarse como obra de referencia indispensable para los especialistas en una disciplina 0 ámbito profesional.

En el sector de la Biblioteconomía y Documentación hay que saludar la reciente publicación de dos anuarios específicos, uno que surge por primera vez en 2008, el Anuario de Bibliotecas Españolas de la Fundación Alonso Quijano, y otro que se consolida en su segunda edición, el Anuario ThinkEPI de El Profesional de la Información.

Para convertirse en obra de referencia, un anuario debe recopilar la más completa información sobre los cambios producidos en el último año, las tendencias de mayor protagonismo o los debates de mayor impacto social. Así, en un anuario de un periódico se espera acceder tanto a una selección de noticias relevantes como a los mejores análisis y artículos de opinión. En este sentido, las aportaciones de las dos obras que aquí se reseñan son complementarias, pues responden a dos concepciones muy diferentes.

"Entre ambas obras reúnen textos de unos cien autores españoles"

El anuario de El Profesional de la Información basa su apuesta en el trabajo realizado a lo largo del año por un think tank, un grupo de expertos que aportan sus análisis y propuestas personales sobre los principales focos de atención que se abren a los profesionales de la Documentación en un sentido amplio. Como elementos que completan esta publicación como una obra de referencia, encontramos un resumen de noticias y un apéndice estadístico.

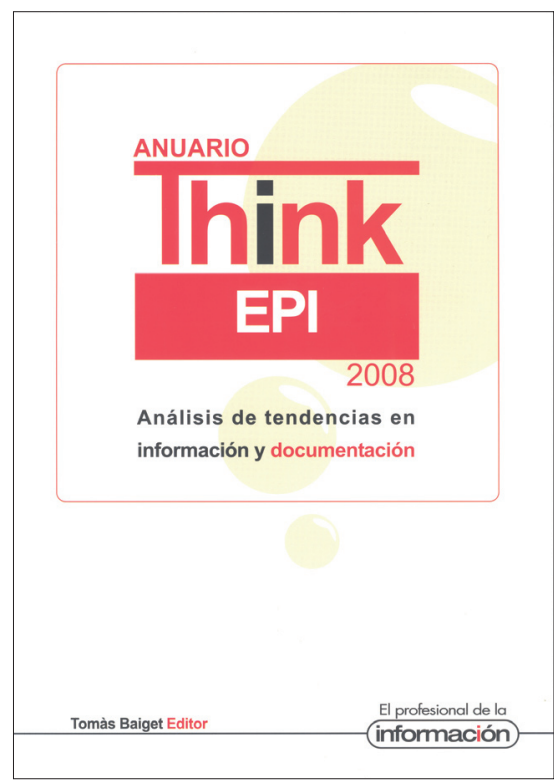

Anuario ThinkEPI 2008. Análisis de tendencias en información y documentación. Tomàs Baiget (ed.): José Antonio Ontalba y Ruipérez (coord.). Barcelona: EPI SCP, 2008. ISSN: 1886-6344

Por su parte la Fundación Alonso Quijano ha buscado colaboraciones de corte más institucional, dando voz a las principales instituciones y organizaciones del sistema bibliotecario español, para realizar una valoración de su situación actual y sus proyectos en curso. Así pues, entre ambas obras reúnen en 
torno a cien autores, que conforman un mosaico con las principales preocupaciones y avances en los servicios bibliotecarios y documentales.

La atención a la terminología es otro punto de interés en este tipo de publicaciones que pretenden orientar sobre tendencias emergentes. Frente a la práctica habitual de los especialistas en Informática, acostumbrados a asumir anglicismos sin ningún recelo, entre los autores de Biblioteconomía y Documentación se ha dedicado tradicionalmente un mayor esfuerzo a fijar las definiciones y el alcance de nuevos términos. Por ello, parece una buena apuesta incluir un glosario, como hace el Anuario de Bibliotecas Españolas, aunque podría haberse limitado a la definición de conceptos de cierta novedad. Sin embargo, carece de un índice, imprescindible para localizar estos neologismos en su contexto. Por su parte, en cambio el Anuario ThinkEpi sí incluye un índice de materias, aunque no un glosario. La búsqueda no siempre esulta fácil, como es habitual en este tipo de herramientas, incluso cuando son realizadas por profeRegister for free at bitps/puww.

"sindicación de contenidos" remite exclusivamente a dos páginas en las que el concepto aparece meramente citado, mientras que deja fuera el artículo de Jorge Franganillo en donde se analiza en profundidad precisamente la oportunidad de este discutido neologismo.

La Fundación Alonso Quijano para el fomento de la lectura es una institución sin ánimo de lucro, creada en el año 2000. Su publicación resalta la estructura y función social del sistema bibliotecario español. A través del anuario se traza el panorama de las bibliotecas en España y sus proyectos en curso, comenzando por la Biblioteca Nacional, y continuando por las bibliotecas públicas, escolares, universitarias y del CSIC o algunas bibliotecas especializadas. Es en este último apartado donde se aprecian algunas lagunas en su cobertura. Por ejemplo, llama la atención la ausencia de la Biblioteca Hispánica, uno de los principales centros españoles tanto por su fondo histórico como por su nivel de adquisiciones, aunque frecuentemente olvidado por no pertenecer al Ministerio de Cultura. El Anuario de Bibliotecas Españolas recoge además un directorio de recursos que reúne fuentes de información, centros de formación y recursos profesionales.

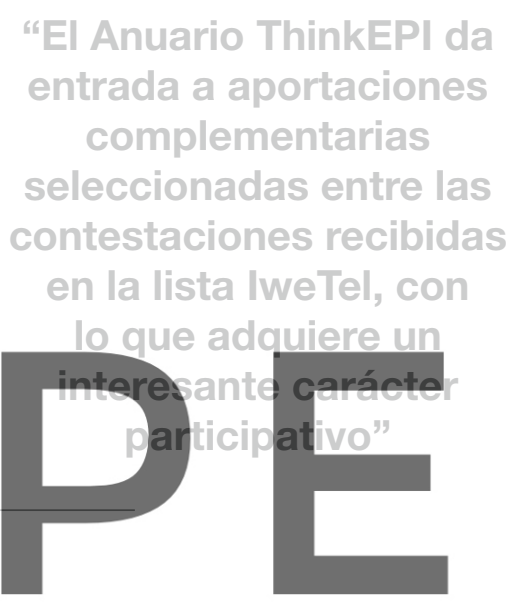

scipedirascamttoed owmiload the Profesional de la Información es un buen modelo de reutilización de contenidos, de forma simular a las prácticas en boga en los medios de comunicación. Se habla de medios líquidos que diseñan sus contenidos con el objetivo de poder editarse en diferentes plataformas; no se trata de rentabilizar unos contenidos reunidos con otro fin, sino de una reutilización perfectamente programada. Con esta filosofía, la edición del anuario aprovecha el trabajo acumulado a lo largo del año 2007 por los expertos del think tank, cuyos artículos se fueron publicando en la lista de distribución IweTel. Esta misma lista y la labor realizada por el sistema de promoción de noticias Documenea, sirven también de base para el resumen anual de las noticias profesionales más relevantes. El anuario es por tanto, resultado de un esfuerzo colectivo continuado a lo largo de todo el año. A las contribuciones difundidas a través de IweTel, se añaden en esta edición de 2008 un resumen y palabras clave para cada artículo. No se refleja la fecha de difusión inicial en la lista, un elemento que sería muy interesante citar, aunque los textos hayan podido ser revisados con posterioridad.

\section{"Destaca la participación social en ambos anuarios, también con diferentes enfoques"}

Otro aspecto que merece destacarse es la participación social, pre-

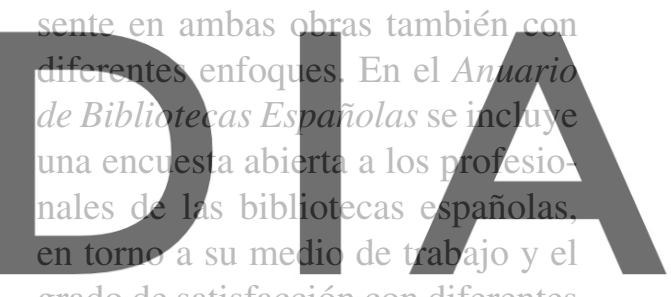

grado de satisfacción con diferentes

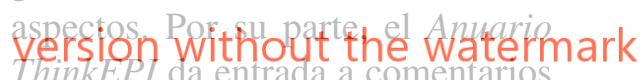
- aportaciones complementarias seleccionadas entre las contestaciones recibidas en la lista IweTel a los artículos del ThinkEPI. Con ello, el anuario adquiere un interesante carácter participativo, integra intervenciones de carácter espontáneo y libre, reduciendo o evitando el carácter elitista de un club de expertos.

En conclusión, se trata de dos obras con enfoques complementarios que resultarán de gran utilidad para profesionales, docentes, investigadores y usuarios.

Luis Rodríguez-Yunta, Centro de Ciencias Humanas y Sociales (CCHS), Consejo Superior de Investigaciones Científicas (CSIC). luis.ryunta@cchs.csic.es 